\title{
Another Curriculum Requirement? Quantitative Reasoning In Economics: Some First Steps
}

Patrick B. O'Neill, University of North Dakota, USA

David T. Flynn, University of North Dakota, USA

\begin{abstract}
In this paper, we describe first steps toward focusing on quantitative reasoning in an intermediate microeconomic theory course. We find student attitudes toward quantitative aspects of economics improve over the duration of the course (as we would hope). Perhaps more importantly, student attitude toward quantitative reasoning improves, in general. This result suggests that economics courses should be considered for inclusion as part of any effort to incorporate quantitative reasoning across the curriculum.
\end{abstract}

Keywords: Economics; Quantitative Reasoning; Curriculum

\section{INTRODUCTION}

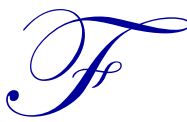

aculty frequently lament the lack of skills among undergraduates and these lamentations often result in curriculum initiatives. Perhaps the most widely known of these is the "writing across the curriculum" initiative which resulted in significant changes in many economics courses. ${ }^{1}$ We may be about to experience another curriculum initiative as there is a concerted effort at many universities to include "quantitative reasoning" or "quantitative literacy" into many and varied courses. ${ }^{2}$ This is good news for economists since so much of what we cover in our courses is quantitative in nature. We examine quantitative reasoning in an intermediate microeconomic theory course. ${ }^{3}$ The starting point is the creation of a survey instrument to measure student attitudes toward quantitative reasoning. We find student attitudes toward quantitative aspects of economics, as well as toward quantitative reasoning in general, improve during the course. These findings suggest economics courses are likely to contribute to any effort to integrate quantitative reasoning across the curriculum.

The paper proceeds as follows. After a brief discussion of quantitative reasoning, we present the attitude toward quantitative reasoning survey instrument. We then describe various aspects of the course and how they relate to the attitudinal survey and then present the survey results. We end with some conclusions and remarks on future research directions.

\footnotetext{
${ }^{1}$ A helpful starting point for information on writing across the curriculum, in general, is the WAC Clearinghouse website at http://wac.colostate.edu/. Seminal works on the use of writing in economics are "Student Writing as a Guide to Student Thinking" by Jerry Petr in Teaching Undergraduates Economics, 1998, edited by William Walstad and Phillip Saunders or "Integrating the Practice of Writing Into Economics Instruction" by W. Lee Hansen in Teaching Economics to Undergraduates, 1998, edited by William Becker and Michael Watts. For a more recent and innovative way to use writing in economics, see The Literary Book of Economics, 2003, edited by Michael Watts.

${ }^{2}$ For an overview of some of these initiatives, see Current Practices in Quantitative Literacy edited by Rick Gillman, The Mathematical Association of America, 2006, or the Quantitative Literacy section of the Mathematical Association of America website at http://www.maa.org/ql/.

${ }^{3}$ The results in this paper come from two sections of Intermediate Microeconomic Theory taught by one of the authors at the University of North Dakota during the Fall 2007 semester.
} 


\section{WHAT IS QUANTITATIVE REASONING (QR)?}

While there is no universally agreed-upon definition of what $\mathrm{QR}$ is, there is agreement on what $\mathrm{Q}$ is not - it is not the same thing as mathematics. ${ }^{4} \mathrm{QR}$ involves mathematical thinking, uses mathematical analysis, is often taught by mathematicians, but it is not identical to mathematics. What, then, is QR? QR is a habit of mind; a way of thinking. Whereas mathematics deals with abstractions (symbols) and generalization, QR involves data (numbers) and context. The literature yields helpful information about the elements of QR (see Table 1) and typical goals of QR courses (see Table 2).

Table 1: Ten Elements of QR ${ }^{5}$

\begin{tabular}{|ll|ll|}
\hline 1. & Confidence with Mathematics & 2. & Cultural Appreciation \\
\hline 3. & Interpreting Data & 4. & Logical Thinking \\
\hline 5. & Making Decisions & 6. & Mathematics in Context \\
\hline 7. & Number Sense & 8. & Practical Skills \\
\hline 9. & Prerequisite Knowledge & 10. & Symbol Sense \\
\hline
\end{tabular}

Table 2: Six Typical Goals of QR Courses ${ }^{6}$

\begin{tabular}{|ll|ll|}
\hline 1. & Work with graphs (create and interpret) & 2. & Statistics (interpret) \\
\hline 3. & Create mathematical models (linear and nonlinear) & 4. & Work with data \\
\hline 5. & $\begin{array}{l}\text { Use technology (graphing calculators, spreadsheets, } \\
\text { statistics programs, math programs) }\end{array}$ & $\begin{array}{l}\text { Explain (most often in writing) the results and meaning of } \\
\text { the math/numbers }\end{array}$ \\
\hline
\end{tabular}

A glance at any of the current textbooks in Intermediate Microeconomic Theory reveals the centrality of many of the items listed above to the content of the course. ${ }^{7}$ These elements and goals formed the basis for our attempt to investigate $\mathrm{QR}$ within an intermediate microeconomic theory course.

\section{QR IN INTERMEDIATE MICROCECONOMIC THEORY}

As with the courses sampled in Gillman (2006), an intermediate microeconomic theory course does not address all of the QR elements and goals. As taught at the University of North Dakota, the course primarily focuses on three of the elements - logical thinking (E4), making decisions (E5), and mathematics in context (E6) - and three of the goals - work with graphs (G1), create mathematical models (G3), and explain the results and meaning of the math/numbers (G6). These elements and goals permeate all aspects of the course - lectures, in-class exercises, outof-class assignments, and exams. More precisely, the course design is related to the elements and goals as presented in Table 3.

\footnotetext{
${ }^{4}$ Indeed, QR appears in the literature under various names, including quantitative literacy or numeracy. On page 5 of Mathematics and Democracy: The Case for Quantitative Literacy, “...quantitative literacy is not the same as statistics, nor is it the same as mathematics. Quantitative literacy is more a habit of the mind - an approach to problems that employs and enhances both statistics and mathematics".

${ }^{5}$ For a detailed description of each of these elements, see pages 8-9 of Mathematics and Democracy: The Case for Quantitative Literacy prepared by The National Council on Education and the Disciplines. Clearly not all of these elements are of equal importance for Microeconomics.

${ }^{6}$ These are typical of the goals from the many courses described in Current Practices in Quantitative Literacy edited by Rick Gillman, The Mathematical Association of America, 2006. It should be noted that the courses generally focused on a subset of these goals rather than all six.

${ }^{7}$ See, for example, Microeconomics by Pindyck and Rubinfeld or Microeconomics and Behavior by Frank.
} 
Table 3: QR Elements and Goals Mapped Into Course Materials

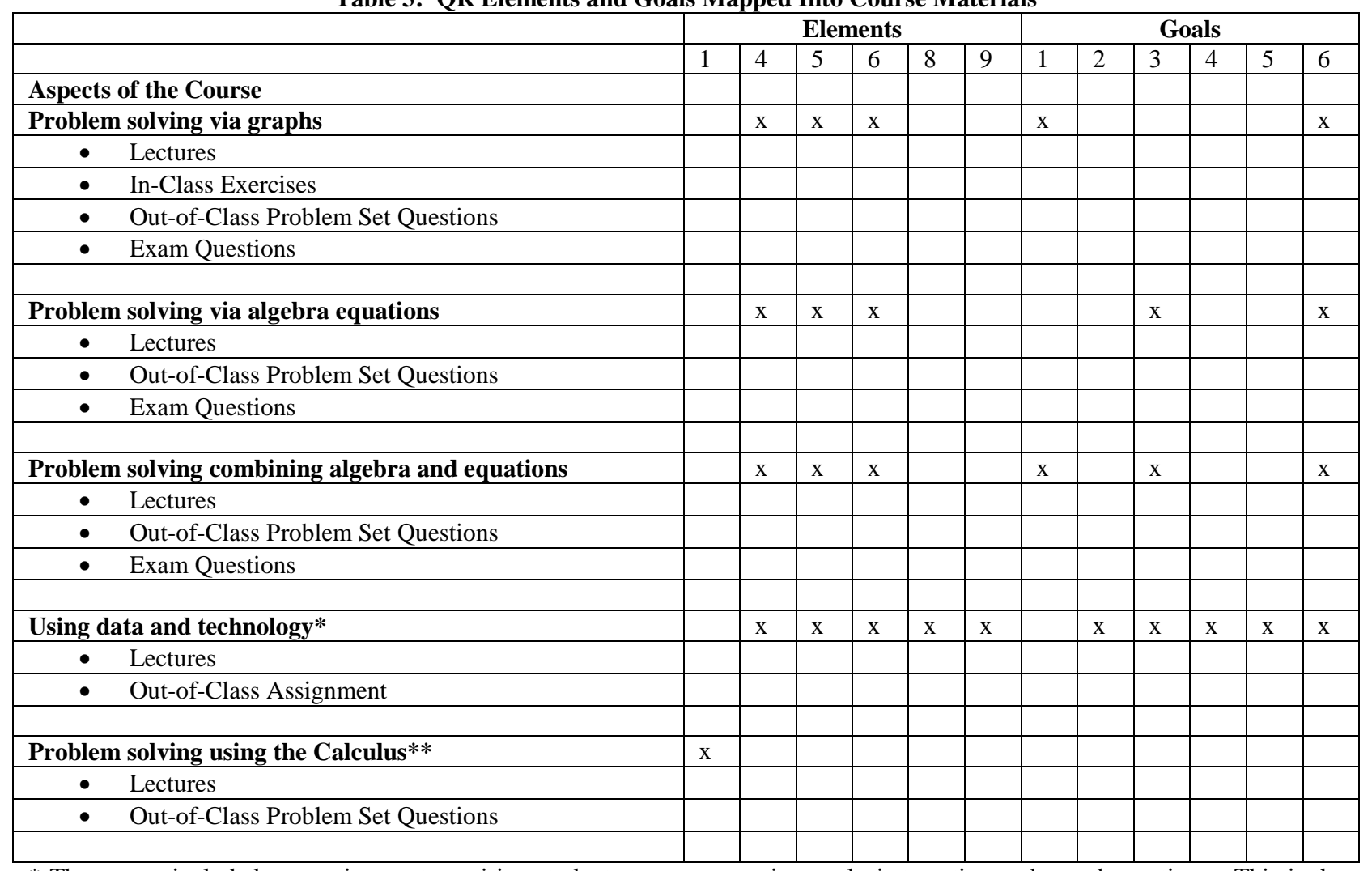

* The course included one assignment requiring students to use regression analysis to estimate demand equations. This is the only part of the course that addresses elements E8 and E9 as well as goals G2, G4, and G5. This assignment constituted 10\% of the course grade.

** No goal is specified as the use of the Calculus was not required in the course. Several examples were presented in class and optional problem set questions requiring the Calculus were offered for student enrichment.

This course design describes QR in intermediate microeconomics from the faculty viewpoint. To move toward the student perspective, we designed a survey instrument which is discussed in the next section.

\section{THE QR SURVEY INSTRUMENT}

We created a survey instrument entitled Attitude Toward Quantitative Reasoning (see Appendix 1). This survey is an adaptation of the Attitude Toward Economics survey commonly used in economics education literature (Soper and Walstad, 1983). Rather than economics per se, we focus on the QR aspects of economics. We also attempt to gain some sense of student attitude toward QR in general. We add together the student responses to generate a number that may be interpreted as an overall indicator of the students' attitudes toward quantitative reasoning. The overall score will range from 20 (least favorable attitude) to 100 (most favorable attitude). The instrument was administered both at the beginning and the end of the course. The survey was completed by 54 students at the beginning of the course and 37 students at the end of the course. The results are presented in Appendix 2. Of more interest are the results from those 34 students who completed the survey at both the beginning and the end of the course. The results from this matched pair sample are presented in Table 4. 
Table 4: Overall Survey Results - Matched Pairs

\begin{tabular}{|l|c|c|c|c|}
\hline & \multicolumn{2}{|c|}{ Start of Course } & \multicolumn{2}{c|}{ End of Course } \\
\hline \multicolumn{1}{|c|}{ Statement } & Mean & Std Dev & Mean & 1.132 \\
\hline 1 & 3.65 & 1.012 & 3.85 & 1.007 \\
\hline 2 & 3.59 & 0.957 & 3.68 & 2.726 \\
\hline 3 & 2.97 & 1.058 & 3.03 & 1.234 \\
\hline 4 & 2.44 & 1.284 & 2.59 & 0.814 \\
\hline 5 & 3.82 & 0.758 & 3.94 & 0.989 \\
\hline 6 & 3.94 & 0.814 & 3.85 & 0.705 \\
\hline 7 & 4.53 & 0.788 & 4.56 & 0.931 \\
\hline 8 & 3.74 & 0.931 & 3.74 & 1.138 \\
\hline 9 & 2.44 & 0.786 & 2.91 & 0.828 \\
\hline 10 & 4.18 & 0.834 & 4.26 & 0.904 \\
\hline 11 & 1.74 & 0.898 & 1.82 & 0.892 \\
\hline 12 & 3.06 & 1.127 & 3.41 & 0.927 \\
\hline 13 & 3.35 & 0.917 & 3.44 & 0.938 \\
\hline 14 & 3.71 & 0.799 & 3.71 & 1.076 \\
\hline 15 & 2.71 & 1.115 & 3.41 & 0.793 \\
\hline 16 & 3.71 & 0.799 & 3.91 & 0.869 \\
\hline 17 & 3.85 & 0.925 & 3.82 & 0.485 \\
\hline 18 & 4.24 & 0.923 & 4.65 & 0.871 \\
\hline 20 & 3.38 & 0.853 & 3.71 & 1.282 \\
\hline
\end{tabular}

We conducted a difference of means test for the overall index, a Course subset, and a Non-Course subset. ${ }^{8}$

The basic version of this test is given as:

$t=\frac{\bar{d} \sqrt{n}}{s_{d}}$

where $\bar{d}$ represents the mean of the pre-test attitudinal response less the post-test attitudinal response and $s_{d}$ is the standard deviation. Table 5 shows the results for the overall index, the Course subset, and the Non-Course subset.

Table 5: Matched Pair Survey Results

\begin{tabular}{|l|c|c|c|c|c|c|}
\hline & \multicolumn{2}{|c|}{ Start of Course } & \multicolumn{2}{c|}{ End of Course } & & \\
\hline \multicolumn{1}{|c|}{ Item } & Mean & Std Dev & Mean & Std Dev & t-value & \\
\hline QR Index & 67.79 & 9.125 & 71.17 & 9.391 & 3.059 & $* * *$ \\
\hline Course & 42.21 & 7.571 & 45.06 & 7.851 & 2.972 & $* *$ \\
\hline Non-Course & 25.59 & 2.986 & 26.09 & 2.968 & 1.314 & $*$ \\
\hline
\end{tabular}

$* * *$ Significant at the $1 \%$ level.

**Significant at the $5 \%$ level.

*Significant at the $10 \%$ level.

The data above reflect a number of interesting results. The QR Index values indicate that student overall attitude toward quantitative reasoning improved by more than three points after taking intermediate microeconomics. The difference of means test indicates that this change is statistically significant at the $1 \%$ level.

\footnotetext{
${ }^{8}$ There are thirteen statements in the Course subset - numbers $1,3,4,5,8,9,10,12,13,15,16,19$, and 20. The remaining seven statements constitute the Non-Course subset. The Course subset consists of statements that are linked to aspects of the course designed to give students practice thinking quantitatively. Specifically, they are linked to the QR elements and goals presented in Tables 1 and 2 .
} 
The Course subset has a range of values from 13 (least favorable attitude) to 65 (most favorable attitude). The Non-Course subset has a range of values from 7 (least favorable attitude) to 35 (most favorable attitude). For the Course subset, there is a $4.39 \%$ improvement in attitude, statistically significant at the $1 \%$ level. For the NonCourse subset, there is a $1.43 \%$ improvement in attitude, statistically significant at the $10 \%$ level. One would expect (perhaps, hope) that using quantitative reasoning tools to solve economics problems throughout a course would lead to an improvement in attitude about using QR in an economics context - and indeed the results for the Course subset provide evidence to support that belief. It is the improvement in the Non-Course subset that is the most important and interesting - for a "quantitative reasoning across the curriculum" movement. Indeed, this result indicates that using QR in an economics context improves student attitude toward QR. In a non-economics context, there is a positive spillover effect on attitudes toward QR in general. This is indeed good news for economists looking to have intermediate microeconomics included in any list of courses fulfilling QR requirements.

\section{CONCLUSION AND FUTURE WORK}

What has been presented here is a first attempt to incorporate quantitative reasoning into an economics course. The findings are cause for celebration. First, we show how an intermediate microeconomic theory course can be utilized to satisfy a typical set of quantitative reasoning goals. Second, we offer a survey instrument designed to evaluate student attitudes toward quantitative reasoning. We find not only an improvement in student attitudes toward the use of quantitative reasoning in solving economics problems over the duration of an intermediate microeconomic theory course, but also a positive spillover effect. That is, student attitudes toward quantitative reasoning, in general (not related to anything specific to economics), improve.

The work presented here is labeled as "first steps." Still to be done is to repeat the survey in another semester to increase the sample size as well as administer the survey in other economics courses. In addition, the nature of the relationship between attitude and performance has not yet been determined.

\section{AUTHOR INFORMATION}

Patrick B. O'Neill is Professor and Clow Banking Fellow in the Department of Economics at the University of North Dakota. He served as Chair of the Department from 2001-2011. He is currently Acting Associate Dean of the College of Business and Public Administration. He teaches courses in principles of macroeconomics, microeconomic theory, and managerial economics. He holds a BA in economics from the University of St. Thomas (St. Paul, MN) and an MA and PhD in economics from Boston College. His research interests include the teaching of economics, the theory of the firm, and the intersection of economics and ethics. E-mail: poneill@bsusiness.und.edu (Corresponding author)

David T. Flynn is Professor and Chairman of the Department of Economics at the University of North Dakota. He also serves as Director of the Bureau of Business \& Economic Research at the University of North Dakota. His teaching interest include economic history, banking, and forecasting. He has an AB in economics from Boston College and a Ph.D. in economics from Indiana University. E-mail: david.flynn@business.und.edu

\section{REFERENCES}

1. Frank, Robert H. Microeconomics and Behavior, 8e, Irwin McGraw-Hill, 2010.

2. Gillman, Rick, editor, Current Practices in Quantitative Literacy The Mathematical Association of America, 2006.

3. Hansen, W. Lee, "Integrating the Practice of Writing Into Economics Instruction" 79 -118 in Teaching Economics to Undergraduates edited by William Becker and Michael Watts, Edward Elgar, 1998.

4. Petr, John "Student Writing as a Guide to Student Thinking" 227-243 in Teaching Undergraduates Economics edited by William Walstad and Phillip Saunders, Irwin McGraw-Hill, 1998.

5. $\quad$ Pindcyk, Robert S. and Daniel L. Rubinfeld, Microeconomics, 7e, Pearson, 2009.

6. Soper, JC and WB Walstad “On Measuring Economic Attitudes” Journal of Economic Education, 14(1), Fall 1983, 4-17. 
7. Steen, Lynn A., editor, Mathematics and Democracy: The Case for Quantitative Literacy The National Council on Education and the Disciplines, 2001.

8. Watts, Michael, editor, The Literary Book of Economics, ISI Books, 2003.

9. Web sites cited: http://wac.colostate.edu/; http://www.maa.org/ql/ 


\section{APPENDIX 1}

\section{Attitudes Toward Quantitative Reasoning Survey}

- $\quad$ 1. I have math anxiety. *

$+\quad$ 2. Mathematics plays an important role in my life.

$+\quad$ 3. I enjoy drawing graphs.

$+\quad$ 4. The Calculus is my friend.

- $\quad$ 5. Solving problems using mathematical tools is very difficult for me. *

$+\quad$ 6. Numbers make sense to me.

- 7. I have trouble balancing my checkbook. *

$+\quad 8$. My previous training in algebra, geometry and statistics is adequate.

$+\quad$ 9. I am comfortable using regression software.

- $\quad$ 10. Algebra scares me. *

$+\quad$ 11. On occasion I read an unassigned book or article in mathematics.

$+\quad$ 12. I know how to determine statistical significance.

$+\quad$ 13. I enjoy thinking quantitatively.

$+\quad$ 14. I use mathematics everyday to help me make decisions.

$+\quad$ 15. I know how to make use of t-statistics.

$+\quad$ 16. I am comfortable using algebra to solve economics problems.

$+\quad$ 17. When given a problem to solve, I prefer to have actual numbers rather than algebraic symbols.

- $\quad$ 18. I have trouble determining how much money to leave for a tip at a restaurant or bar. *

$+\quad$ 19. I am comfortable using graphs to solve economics problems.

$+\quad 20$. I am comfortable using the Calculus to solve economics problems.

\section{Response Code:}

$1=$ strongly disagree $; 2=$ disagree $; 3=$ undecided $; 4=$ agree $; 5=$ strongly agree

+ Indicates the positive response is strongly agree

- Indicates the positive response is strongly disagree

* Indicates a reverse-coded item 


\section{APPENDIX 2}

Attitudes Toward Quantitative Reasoning Survey Results

\begin{tabular}{|c|c|c|c|c|}
\hline \multirow[b]{2}{*}{ Statement } & \multicolumn{2}{|c|}{$\begin{array}{c}\text { Start of Course } \\
(N=54)\end{array}$} & \multicolumn{2}{|c|}{$\begin{array}{l}\text { End of Course } \\
\quad(\mathbf{N}=37)\end{array}$} \\
\hline & Mean & Std Dev & Mean & Std Dev \\
\hline 1 & 3.83 & 1.06 & 3.76 & 1.19 \\
\hline 2 & 3.72 & 0.96 & 3.62 & 1.01 \\
\hline 3 & 3.2 & 1 & 3.05 & 0.85 \\
\hline 4 & 2.65 & 1.31 & 2.59 & 1.24 \\
\hline 5 & 3.89 & 0.82 & 3.86 & 0.86 \\
\hline 6 & 4.04 & 0.75 & 3.84 & 0.96 \\
\hline 7 & 4.54 & 0.72 & 4.54 & 0.73 \\
\hline 8 & 3.83 & 0.91 & 3.68 & 0.94 \\
\hline 9 & 2.56 & 0.86 & 2.97 & 1.14 \\
\hline 10 & 4.19 & 0.89 & 4.22 & 0.82 \\
\hline 11 & 1.91 & 1.03 & 1.86 & 0.95 \\
\hline 12 & 3.2 & 1.07 & 3.46 & 0.87 \\
\hline 13 & 3.39 & 0.94 & 3.43 & 0.9 \\
\hline 14 & 3.72 & 0.9 & 3.68 & 0.91 \\
\hline 15 & 2.94 & 1.12 & 3.38 & 1.06 \\
\hline 16 & 3.77 & 0.8 & 3.92 & 0.8 \\
\hline 17 & 3.69 & 1.04 & 3.81 & 0.84 \\
\hline 18 & 4.19 & 0.89 & 4.57 & 0.6 \\
\hline 19 & 3.61 & 0.86 & 3.65 & 0.86 \\
\hline 20 & 2.91 & 1.09 & 2.84 & 1.24 \\
\hline QR Index & 69.7 & 10.2 & 70.4 & 9.33 \\
\hline
\end{tabular}

